David P. Inwald

Warwick Butt

Robert C. Tasker

\section{Fluid resuscitation of shock in children: what, whence and whither?}

Received: 27 May 2015

Accepted: 28 May 2015

Published online: 19 June 2015

(C) Springer-Verlag Berlin Heidelberg and ESICM 2015

D. P. Inwald ( $\square)$

Paediatric Intensive Care Unit, St Mary's Hospital, Imperial College Healthcare NHS Trust, London, England, UK

e-mail: d.inwald@imperial.ac.uk

Tel.: + 442033121625

W. Butt

Department of Paediatrics, University of Melbourne, Murdoch Children's Research Institute and Royal Children's Hospital, Melbourne, Australia

R. C. Tasker

Departments of Neurology and Anesthesiology, Harvard Medical School and Boston Children's Hospital, Boston, MA, USA

\section{What?}

Infectious diseases remain a major cause of mortality and morbidity in the developed world, accounting for more than $25 \%$ of deaths in children under the age of 5 years in Europe [1]. Even with improved recognition and management serious morbidity in survivors is high. As a pediatric critical care community we have often blamed inadequate fluid resuscitation for this finding, a consequence of failing to follow guidelines recommending aggressive fluid resuscitation, which we have seen as "acute medicine's great triumph for children" [2]. In an article recently published in Intensive Care Medicine Bhaskar et al. [3] bring to our attention the problem of early fluid accumulation in children treated for shock and its association with pediatric intensive care unit (PICU) mortality. As a concept, intolerable excess of fluid and tissue storage by inundation, is not new-Walter Cannon introduced it at the same time as he defined homeostasis [4] — but it is worth reviewing the current article in the context of where we have come from and where we should be going with fluid management.

\section{Whence?}

Early studies of experimental hemorrhage by Alfred Blalock [5] found that "shock" appeared after $20-30 \mathrm{~mL} /$ $\mathrm{kg}$ of blood loss, and was fatal after $40 \mathrm{~mL} / \mathrm{kg}$. Fluid resuscitation restored cardiac output. Since then, regardless of cause, rapid bolus fluid resuscitation has become integral to emergency management of shock states. This includes emergency management of children with severe sepsis. The current American College of Critical Care Medicine-pediatric life support (ACCM-PALS) guidelines for hemodynamic support of pediatric and neonatal septic shock recommend bolus fluid resuscitation with $20 \mathrm{~mL} / \mathrm{kg}$ (up to a total of $200 \mathrm{~mL} / \mathrm{kg}$ ) during the first hour of emergency assessment and treatment [6]. The assumption is that transcapillary leak of fluid leads to relative and ongoing intravascular hypovolemia.

The clinical literature supporting the ACCM-PALS recommendations consists of retrospective studies involving small numbers of children [7-9]. There are no data from prospective clinical trials. However, there is now increasing evidence that fluid overload in critical illness is deleterious. In Africa, the recent FEAST (fluid expansion as supportive therapy) multicenter randomized controlled trial (RCT) compared bolus fluid resuscitation of $20 \mathrm{~mL} / \mathrm{kg}$ with maintenance fluid in over 3000 children with severe infection and reported a $30 \%$ increase in mortality associated with bolus fluid resuscitation [10]. Even though the study was conducted in a low-income setting, without PICU facilities, FEAST has raised considerable uncertainty and highlighted the lack of evidence for bolus fluid resuscitation for children with septic shock in middle- and high-income settings [11]. 
Table 1 Recent PICU studies (2011-2015) demonstrating the association of poor outcome with fluid overload during admission

\begin{tabular}{|c|c|c|c|}
\hline Reference & Clinical condition & $n$ & Significant outcomes \\
\hline Flori et al. [12] & Acute lung injury & 320 & $\begin{array}{l}\text { Positive fluid balance (in } 10 \mathrm{~mL} / \mathrm{kg} \text { increments) was associated } \\
\text { with increased ventilation days and mortality }\end{array}$ \\
\hline Arikan et al. [13] & General PICU population & 80 & $\begin{array}{l}\text { Fluid overload ( } \geq 15 \%) \text { was associated with oxygenation index, } \\
\text { ventilation days, and LOS }\end{array}$ \\
\hline Valentine et al. [14] & Acute lung injury & 168 & $\begin{array}{l}\text { Increasing fluid balance on day } 3 \text { is associated with fewer } \\
\text { ventilator-free-days at } 28 \text { days }\end{array}$ \\
\hline Sinitsky et al. [15] & General PICU population & 636 & $\begin{array}{l}\text { Fluid overload at } 48 \mathrm{~h} \text { was associated with oxygenation index } \\
\text { and ventilation days }\end{array}$ \\
\hline
\end{tabular}

$R R T$ renal replacement therapy, LOS length of stay

As shown in a developed world setting by Bhaskar et al. [3], in those patients who survive to PICU admission, ongoing enthusiastic fluid resuscitation, along with maintenance fluid administration, leads to fluid overload, which in some cases is massive and potentially harmful. The authors examined, retrospectively, 114 children admitted to their PICU with a variety of shock states and found that early fluid overload (EFO, defined as fluid accumulation of at least $10 \%$ of admission body weight during the initial 3 days of admission) was associated with mortality, even controlling for severity of illness. Patients with EFO were also more likely to develop respiratory failure and survivors had significantly more ventilation days.

At one level these data are not surprising; in essence, sicker patients in shock receiving more fluids do less well. However, this observation along with similar observations from other recent studies ([12-15], see Table 1) point to the need to examine the whole pathway-from initial presentation in the ED through to PICU admission-with better clinical tools and better studies.

\section{Whither?}

During emergency treatment starting during the pre-PICU presentation and continuing through to the early phase of PICU admission, resuscitation fluid is administered according to ACCM-PALS guidelines in which the target is "adequate blood pressure and clinical monitors of cardiac output including heart rate, quality of peripheral pulses, capillary refill, level of consciousness, peripheral skin temperature, and urine output" [6]. This process is an inexact science, which is complicated by highly individual pediatric physiology patterns (e.g., distributive, hypovolemic, cardiogenic, and vasodilatory shock) variably contributing to clinical disease phenotypes [16].
Furthermore, clinical assessment of cardiac output in children is notoriously unreliable [17]. Even invasive monitoring may be unhelpful. The recommendation to titrate therapy to mixed-venous oxygen-hemoglobin saturation of at least $70 \%$ has now also been challenged by large studies in adult patients [18].

One major limitation of the report by Bhaskar et al. [3], which is shared with other PICU studies (Table 1), is the failure to take into account all of the fluid administered to the child, starting with resuscitation in the prePICU phase of care. This volume will certainly have the potential to impact on fluid overload in the PICU, especially if current ACCM-PALS guidelines are followed (see above, $20-200 \mathrm{~mL} / \mathrm{kg}$ in the first hour of assessment). Thus while the findings of Bhaskar et al. [3]—and for that matter all recent PICU fluid studies [12-15] - are interesting, they are not conclusive. What is needed now, as Bhaskar et al. [3] suggest, are RCTs that better assess the impact of early fluid accumulation on outcome.

Two such pediatric fluid resuscitation RCTs are now at different stages of development in the developed world. The SQUEEZE (septic shock reversal is quicker in pediatric patients randomized to an early goal directed fluid-sparing strategy vs. usual care) study is a Canadian RCT that will essentially compare fluid to inotrope therapy (NCT01973907, ClinicalTrials.gov). The FiSh (Fluids in Shock) study (UK Health Technology Assessment Programme 13/04/105) will look at different volume fluid bolus resuscitation in community-acquired severe sepsis. There is also a pressing need to develop new hemodynamic end points for titration of resuscitationparameters that are non-invasive, reproducible, and reliable.

Conflicts of interest DI is Principal Investigator on FiSh. On behalf of all authors, the corresponding author states that there is no other conflict of interest. 


\section{References}

1. Black RE, Cousens S, Johnson HL et al (2010) Global, regional, and national causes of child mortality in 2008: a systematic analysis. Lancet 375:1969-1987

2. Carcillo JA, Tasker RC (2006) Fluid resuscitation of hypovolemic shock: acute medicine's great triumph for children. Intensive Care Med 32:958-961

3. Bhaskar P, Dhar AV, Thompson M, Quigley R, Modem V (2015) Early fluid accumulation in children with shock and ICU mortality: a matched casecontrol study. Intensive Care Med. doi:10.1007/s00134-015-3851-9

4. Cannon WB (1929) Organization for physiological homeostasis. Physiol Rev 9:399-431

5. Blalock A (1927) Mechanism and treatment of experimental shock I. Shock following hemorrhage. Arch Surg 15:762-798

6. Brierley J, Carcillo JA, Choong K et al (2009) Clinical practice parameters for hemodynamic support of pediatric and neonatal septic shock: 2007 update from the American College of Critical Care Medicine. Crit Care Med 37:666-688

7. Carcillo JA, Davis AL, Zaritsky A (1991) A role of early fluid resuscitation in pediatric septic shock. JAMA 266:1242-1245
8. Booy R, Habibi P, Nadel S, de Munter C, Britto J, Morrison A, Levin M (2001) Reduction in case fatality rate from meningococcal disease associated with improved healthcare delivery. Arch Dis Child 85:386-390

9. Han YY, Carcillo JA, Dragotta MA, Bills DM, Watson RS, Westerman ME, Orr RA (2003) Early reversal of pediatric-neonatal septic shock by community physicians is associated with improved outcome. Pediatrics 112:793-799

10. Maitland K, Kiguli S, Opoka RO et al (2011) Mortality after fluid bolus in African children with severe infection. N Engl J Med 364:2483-2495

11. Duke T (2011) What the African fluidbolus trial means. Lancet 378:1685-1687

12. Flori HR, Church G, Liu KD, Gildengorin G, Matthay MA (2011) Positive fluid balance is associated with higher mortality and prolonged mechanical ventilation in pediatric patients with acute lung injury. Crit Care Res Pract 854142. doi: $10.1155 / 2011 / 854142$

13. Arikan AA, Zappitelli M, Goldstein S, Naipaul A, Jefferson LS, Loftis L (2012) Fluid overload is associated with impaired oxygenation and morbidity in critically ill children. Pediatr Crit Care Med 13:253-258
14. Valentine SL, Sapru A, Higgerson RA et al (2012) Fluid balance in critically ill children with acute lung injury. Crit Care Med 40:2883-2889

15. Sinitsky L, Walls D, Nadel S, Inwald DP (2015) Fluid overload at 48 hours is associated with respiratory morbidity but not mortality in a general PICU: retrospective cohort study. Pediatr Crit Care Med 16:205-209

16. Deep A, Goonasekera CD, Wang Y, Brierley J (2013) Evolution of haemodynamics and outcome of fluidrefractory septic shock in children. Intensive Care Med 39:1602-1609

17. Tibby SM, Hatherill M, Marsh MJ, Murdoch IA (1997) Clinicians' abilities to estimate cardiac index in ventilated children and infants. Arch Dis Child 77:516-518

18. Angus DC, Barnato AE, Bell D et al (2015) A systematic review and metaanalysis of early goal-directed therapy for septic shock: the ARISE, ProCESS and ProMISe investigators. Intensive Care Med. doi: 10.1007/s00134-015-3822-1 